\title{
Does vitamin D play a significant role in type 2 diabetes?
}

\author{
Jayesh J Sheth ${ }^{*}$, Ankna Shah ${ }^{1}$, Frenny J Sheth ${ }^{1}$, Sunil Trivedi ${ }^{1}$, Mamta Lele ${ }^{2}$, Navneet Shah ${ }^{3}$, Premal Thakor ${ }^{4}$ and \\ Rama Vaidya ${ }^{2}$
}

\begin{abstract}
Background: Vitamin D deficiency reportedly is associated with type 2 diabetes (T2DM). We aim to examine whether 25-hydroxyvitamin D (25OHD) has clinically significant influence on hemoglobin glycation (HbA1c) and insulin resistance (HOMA-IR) in T2DM subjects.

Methods: Present study was carried out in 912 subjects (429 T2DM cases and 483 non-diabetic controls) from Western India. The enrolled study subjects were investigated for biochemical parameters like FBS, PPBS, HbA1c, $\mathrm{Fl}, \mathrm{HOMA}-\mathrm{IR}$ and 25OHD levels in blood.

Results: Vitamin D deficiency was seen in $91.4 \%$ and $93.0 \%$ of T2DM cases and control subjects respectively. There was no association of serum 25OHD deficiency on HbA1c or HOMA-IR in T2DM cases ( $p=0.057 \& p=0.257$ respectively) and in control subjects ( $p=0.675 \& p=0.647$ respectively).

Conclusion: Our findings suggests that though vitamin D deficiency is prevalent in T2DM and non-diabetic subjects, its role in hemoglobin glycation and insulin resistance could not be established.
\end{abstract}

Keywords: Diabetes, Vitamin D, HbA1c, HOMA-IR

\section{Background}

Type 2 Diabetes Mellitus (T2DM) is the commonly seen endocrine disorder characterized by hyperglycemia [1]. The International Diabetes Federation (IDF) estimates around 61.3 million diabetic individuals (2011) in India that is further set to increase to 101.2 million with a global estimate of 552 million by the year 2030 [2]. There are several factors that seem to play a role in its development including genetic, lifestyle, environmental and nutritional conditions. Amongst nutritional factors, vitamin $\mathrm{D}$ is likely to have an important role either in glycemic control or in attenuating diabetic complications [3-5]. The probable mechanisms indicating the role of vitamin $\mathrm{D}$ in glucose homeostasis is likely to be through beta cell dysfunction and insulin resistance in cases with vitamin $\mathrm{D}$ deficiency [6,7]. A negative correlation between serum glucose and insulin levels with 25OHD and a positive correlation with insulin sensitivity has been observed in

\footnotetext{
* Correspondence: jshethad1@gmail.com

'Department of Biochemistry and Molecular Genetics, FRIGE's Institute of Human Genetics, FRIGE House, Jodhpur Gam Road, Satellite, Ahmedabad 380015, India

Full list of author information is available at the end of the article
}

several human and animal model studies [6-9]. It has also been observed that vitamin D supplementation can improve insulin secretion and reduce insulin resistance in T2DM and non-diabetic subjects [7]. Thus, accumulating the evidence from several studies, vitamin $\mathrm{D}$ is likely to have a role in T2DM and Hb-glycation [10]. Nonetheless, the relationship between serum 25OHD with hemoglobin glycation (HbA1c) [11] and insulin resistance [12] in T2DM has not been extensively studied except for one report from US adult population with T2DM and non-diabetic subjects [11] and none from Western Indian population. Hence, present study was proposed to examine the association of vitamin D (25OHD) levels with HbA1c and HOMA-IR in this population.

\section{Methods \\ Subjects}

The present prospective cross sectional study was conducted after taking Foundation for Research in Genetics and Endocrinology (FRIGE) institutional ethics committee approval for 912 subjects (429 T2DM cases and 483 
non-diabetic controls) of both genders with age ranging from 25 to 86 years. They were selected between April, 2012 to July, 2014 from the Out Patient Departments (OPD) of various diabetologists and through weekly camps at the institute. The participants of the current study were enrolled from an urban metropolitan western Indian population. The inclusion criteria for T2DM subjects were (a) age ( $\geq 25$ years); (b) duration of diabetes ( $\geq 6$ months); and (c) plasma glucose levels (FBS $\geq 126.0$ $\mathrm{mg} / \mathrm{dl}$ ) [13]. Control subjects recruited in the study were non-diabetic with an inclusion criterion of (a) age ( $\geq 25$ years); (b) HbA1c level $\leq 6.5 \%$; and (c) plasma glucose levels $(\mathrm{FBS} \leq 110.0 \mathrm{mg} / \mathrm{dl})$. An institutional ethical committee approval and written informed consent was obtained from all the subjects. Subjects with Type 1 Diabetes, lactating and pregnant mothers, those with concomitant illness and intake of vitamin D supplements were excluded from the study. Anthropometric parameters such as age, BMI, waist circumference, waist-hip ratio and duration of diabetes (in T2DM subjects) were recorded for all the study subjects.

Serum levels of 25OHD were stratified into normal $(\geq 30 \mathrm{ng} / \mathrm{ml})$, insufficient ( $\geq 20$ to $<30 \mathrm{ng} / \mathrm{ml})$ and deficient $(<20 \mathrm{ng} / \mathrm{ml})$ [14]. Subsequently, for this study, we considered all 25OHD values of $<20 \mathrm{ng} / \mathrm{ml}$ as vitamin D deficient and $\geq 20 \mathrm{ng} / \mathrm{ml}$ as non-deficient, with regard to the biological interval used in our laboratory.

\section{Anthropometric indices}

Weight was measured with light clothes without shoes using digital scale (to the nearest $0.1 \mathrm{~kg}$ ). Height was measured without shoes using stadiometer (to the nearest $0.1 \mathrm{~cm}$ ). Waist circumference was measured (to the nearest $0.1 \mathrm{~cm}$ ). BMI was calculated using the equation "BMI = weight $/$ height $^{2}\left(\mathrm{~kg} /\right.$ meter $\left.^{2}\right) "$.

\section{Sample collection and handling}

Blood samples were collected in fluoride and serum vaccutainers between 8 to $11 \mathrm{AM}$ after 12 hours fasting for biochemical assays [fasting blood sugar (FBS), glycosylated hemoglobin (HbA1c), fasting insulin (FI), HOMA-IR, and vitamin D (25OHD) estimation]. Blood was collected again post 2 hours of consuming non-standardized meal for post prandial blood sugar (PPBS) estimation for T2DM subjects while non-diabetic control subject were not investigated for PPBS. Serum was separated within 30-45 minutes, aliquoted and stored at $-20^{\circ} \mathrm{C}$ till analysis.

\section{Biochemical investigations}

All subjects were investigated for biochemical parameters such as FBS \& PPBS, HbA1c, FI, HOMA-IR and 25OHD. FBS and PPBS were determined from plasma by commercially available biochemical kits using an autoanalyzer system (BTS 330, Biosystem, Spain). HbA1c level were measured using affinity assay method by NycoCard reader-II (Axis-Shield, Norway) from whole blood. FI levels were measured by Immune Radiometric Assay (IRMA) using commercial kit (Immunotech, France) in $\gamma$-counter system (PC-RIA.MAS, Stratec Biometrical System AG, Germany). Insulin resistance was calculated by the Homeostasis Model of Assessment-Insulin Resistance Index (HOMA-IR) [as $(\mathrm{FI} \times \mathrm{FBS}) / 405$, where FI: Fasting Insulin and FBS: Fasting Blood Sugar] [15]. Serum concentrations of 25-hydroxyvitamin D (25OH-D2 and $25 \mathrm{OH}-\mathrm{D} 3)$ were assessed by ELISA method performed on micro-titer plates using ELISA kit (Demeditec Diagnostics GmbH, Germany).

\section{Statistical analysis}

The subjects were recruited based on consecutive sampling technique. The sample size yielded a margin of error of $3.1 \%$ of the study with confidence limit of $95 \%$ with on-line calculator [16]. False positive error rate/ Type I error was 0.05. Comparisons of all variables like FBS, PPBS, HbA1c, fasting insulin and HOMA-IR were performed with Student's $t$-test. Value of HbA1c was given as percentage of total hemoglobin and values of all other glucose parameters were given in $\mathrm{mg} / \mathrm{dl}$. All values are expressed as mean \pm standard deviation. Linear regression analysis was also performed. The analysis was carried out with IBM-SPSS v15.0. p values (two tailed, $<0.05)$ were considered as statistically significant.

\section{Results}

Vitamin D deficiency $(<20 \mathrm{ng} / \mathrm{ml})$ was a common finding in this cohort affecting approximately $91.4 \%$ and $93.0 \%$ of T2DM cases (Group-1) and control subjects (Group-2) respectively. Hence, both the groups were further subdivided in to vitamin $\mathrm{D}$ deficient $(25 \mathrm{OHD}<20 \mathrm{ng} / \mathrm{ml})$ and non-deficient $(25 \mathrm{OHD} \geq 20 \mathrm{ng} / \mathrm{ml})$. Anthropometric indices such as age, BMI, waist circumference, waist-hip ratio, duration of diabetes, and biochemical parameters such as FBS, HbA1c, FI and HOMA-IR were compared between the vitamin $\mathrm{D}$-deficient and non-deficient group in addition to case and control subjects where notably no significant difference was observed as shown in Table 1. All the patients and controls were city dwellers; majority of them were office workers or housewives and connected to non-strenuous life style with minimal aerobic exercise during the day. Increased BMI $\left(>25 \mathrm{~kg} / \mathrm{m}^{2}\right)$ was seen in $64.5 \%$ (277/429) of T2DM subjects. Higher BMI was observed in $65.2 \%(255 / 391)$ of vitamin D deficient (low serum 25OHD) patients as opposed to $60.0 \%$ (21/35) of non-deficient (normal serum 25OHD) T2DM subjects. Similarly, increased waist circumference (Females $>80 \mathrm{cms}$, Males: $>90 \mathrm{cms}$ ) was above upper limit of normal in $81.5 \%$ (350/429) of subjects; increased in 81.9\% (319/390) of vitamin D deficient versus $85.7 \%$ (30/35) of non-deficient 
Table 1 Baseline demographic and biochemical indices of T2DM cases and control subjects according to their vitamin D status

\begin{tabular}{|c|c|c|c|c|c|c|}
\hline \multirow{2}{*}{$\begin{array}{l}\text { Parameters } \\
(T=912)\end{array}$} & \multicolumn{3}{|l|}{ T2DM Cases $(\mathrm{N}=429)$} & \multicolumn{3}{|c|}{ Non-diabetic Controls $(\mathrm{N}=483)$} \\
\hline & $\begin{array}{l}\text { Serum } 25 O H D<20 \mathrm{ng} / \mathrm{ml} \\
\text { Mean } \pm \text { SD } \\
(\mathrm{n}=392)\end{array}$ & $\begin{array}{l}\text { Serum } 250 H D \geq 20 \mathrm{ng} / \mathrm{ml} \\
\text { Mean } \pm S D \\
(\mathrm{n}=37)\end{array}$ & $p$ value & $\begin{array}{l}\text { Serum } 25 O H D<20 \mathrm{ng} / \mathrm{ml} \\
\text { Mean } \pm \text { SD } \\
(\mathrm{n}=449)\end{array}$ & $\begin{array}{l}\text { Serum } 250 H D \geq 20 \mathrm{ng} / \mathrm{ml} \\
\text { Mean } \pm \text { SD } \\
(\mathrm{n}=34)\end{array}$ & $\mathrm{p}$ value \\
\hline \multicolumn{7}{|c|}{ Anthropometric indices } \\
\hline Age (Years) & $56.37 \pm 10.34$ & $57.79 \pm 12.19$ & 0.44 & $48.36 \pm 12.78$ & $51.44 \pm 13.51$ & 0.18 \\
\hline BMI $\left(\mathrm{Kg} / \mathrm{m}^{2}\right)$ & $27.17 \pm 5.14$ & $26.50 \pm 3.93$ & 0.44 & $25.78 \pm 4.54$ & $26.68 \pm 5.20$ & 0.27 \\
\hline WC (cm) & $96.99 \pm 10.68$ & $94.31 \pm 9.21$ & 0.14 & $92.10 \pm 10.71$ & $91.59 \pm 10.61$ & 0.78 \\
\hline WHR & $0.94 \pm 0.10$ & $0.93 \pm 0.07$ & 0.55 & $0.91 \pm 0.07$ & $0.89 \pm 0.08$ & 0.11 \\
\hline $\begin{array}{l}\text { Duration of } \\
\text { T2DM (Years) }\end{array}$ & $8.30 \pm 7.26$ & $11.23 \pm 10.55$ & $0.03^{*}$ & - & - & - \\
\hline \multicolumn{7}{|c|}{ Biochemical indices } \\
\hline FBS (mg/dl) & $150.43 \pm 64.51$ & $138.80 \pm 47.09$ & 0.29 & $88.18 \pm 12.11$ & $87.88 \pm 13.51$ & 0.89 \\
\hline PPBS (mg/dl) & $190.72 \pm 70.50$ & $187.42 \pm 76.74$ & 0.79 & - & - & - \\
\hline HbA1c (\%) & $8.36 \pm 1.79$ & 8. $26 \pm 2.21$ & 0.75 & $5.67 \pm 0.49$ & $5.67 \pm 0.54$ & 0.82 \\
\hline $\mathrm{FI}$ (ulU/ml) & $11.29 \pm 6.95$ & $8.27 \pm 4.17$ & $0.01^{*}$ & $12.11 \pm 5.45$ & $10.00 \pm 5.00$ & $0.03^{*}$ \\
\hline HOMA-IR & $3.93 \pm 3.62$ & $3.04 \pm 2.24$ & $0.04^{*}$ & $2.71 \pm 1.60$ & $2.20 \pm 1.24$ & 0.08 \\
\hline
\end{tabular}

By student's $t$-test, *: Significant, SD: Standard deviation.

BMI: Body mass index, WC: Waist circumference, WHR: Waist-Hip-Ratio.

FBS: Fasting Blood Sugar, PPBS: Post-Prandial Blood Sugar, HbA1c: Glycated hemoglobin, Fl: Fasting Insulin, HOMA-IR: Homeostasis Model of Assessment-Insulin

Resistance Index.

Vitamin D-Deficient: $250 \mathrm{HD}<20 \mathrm{ng} / \mathrm{ml}$.

Vitamin D-Non-deficient: $25 \mathrm{OHD} \geq 20 \mathrm{ng} / \mathrm{ml}$.

T2DM subjects. The waist : hip ratio (WHR) also followed a similar pattern of increased WHR (Females: $>0.85$, Males: $>0.90)$ in $83.2 \%(357 / 29)$ of T2DM subjects; $83.8 \%$ (328/391) of vitamin D deficient vs $80.0 \%$ (28/35) of vitamin D non-deficient T2DM subjects.

Results from linear regression analysis indicate that vitamin D deficiency did not have any statistically significant association with HbA1c levels in both the groups [T2DM: $\mathrm{r}^{2}=0.009, \mathrm{p}=0.057$ (95\% CI $=-0.095$ to 0.003$)$ and Control: $\mathrm{r}^{2}=0.000, \mathrm{p}=0.675$ (95\% $\mathrm{CI}=-0.016$ to $0.010)$ ] respectively. Similarly, no association was detected in subjects of both the groups with normal vitamin $\mathrm{D}$ levels and HbA1c levels [T2DM: $\mathrm{r}^{2}=0.111, \mathrm{p}=0.045$ (95\% $\mathrm{CI}=-0.156$ to -0.002$)$ and Control: $\mathrm{r}^{2}=0.000, \mathrm{p}=0.964$ $(95 \% \mathrm{CI}=-0.011$ to 0.010$)]$ respectively as shown in Figure 1.

Additionally, linear regression analysis results between vitamin $\mathrm{D}$ levels and HOMA-IR indicate that vitamin D deficiency did not have any statistically significant association with HOMA-IR in both the groups [T2DM: $\mathrm{r}^{2}=0.003, \mathrm{p}=0.257(95 \% \mathrm{CI}=-0.157$ to 0.042$)$ and Control: $r^{2}=0.000, p=0.647$ (95\% CI $=-0.053$ to 0.035 ) ] respectively. Likewise, no association was seen in subjects of both the groups with normal vitamin D levels and HOMA-IR levels [T2DM: $\mathrm{r}^{2}=0.049, \mathrm{p}=0.186$ (95\% CI $=-0.135$ to 0.027 ) and Control: $\mathrm{r}^{2}=0.039, \mathrm{p}=0.221$
(95\% CI $=-0.034$ to 0.013$)]$ respectively as described in Figure 2.

\section{Discussion}

The increasing incidence of T2DM is taking a great toll of health resources. This has laid a number of research studies related to life style, environmental and nutritional factors in an attempt to ameliorate its burden. The diverse effect of vitamin D on glucose and calcium homeostasis [17] has made it an ideal contender to know its role in glycemic control in T2DM. India being a vast tropical country geographically spreading from $8.4^{\circ} \mathrm{N}$ latitude to $37.6^{\circ} \mathrm{N}$ latitude, it is expected that sufficient sunlight is received throughout the year $[14,18,19]$. Regardless of this vitamin D deficiency has been observed more commonly in earlier studies from India [14,19]. The present study has also shown a higher incidence (91.4\%) of vitamin D deficiency in overall recruited subjects indicating that both T2DM (91.4\%) subjects and non-diabetic control subjects (93.0\%) were equally deficient. This is in accordance with other studies demonstrating low serum vitamin D levels in $70 \%$ to $100 \%$ populations across India $[14,18,19]$. This is likely to be due to increased skin pigmentation, low exposure to direct sunlight, obesity and malabsorption, as has been observed by several studies from India $[14,18,19]$. It has 


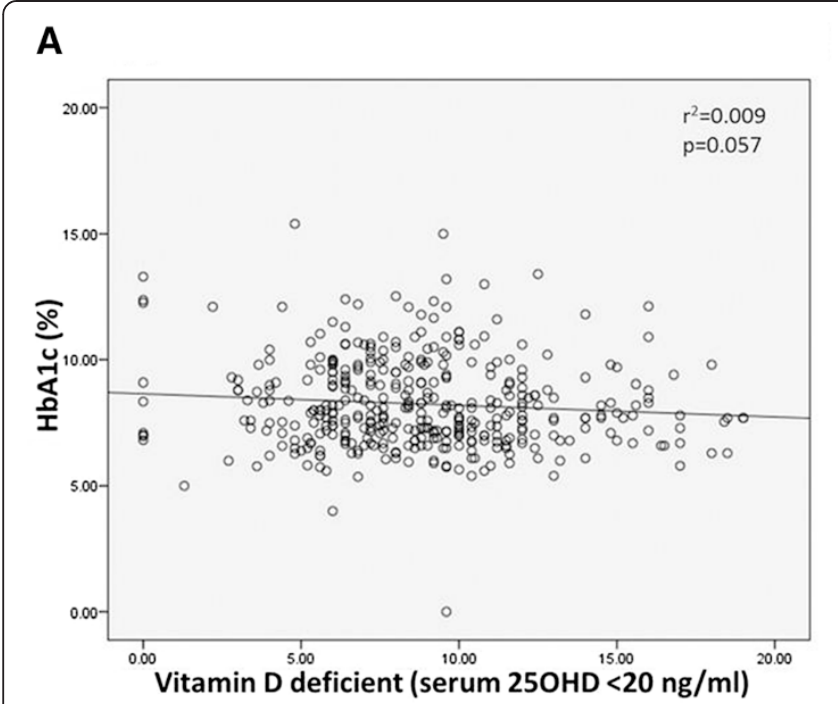

B

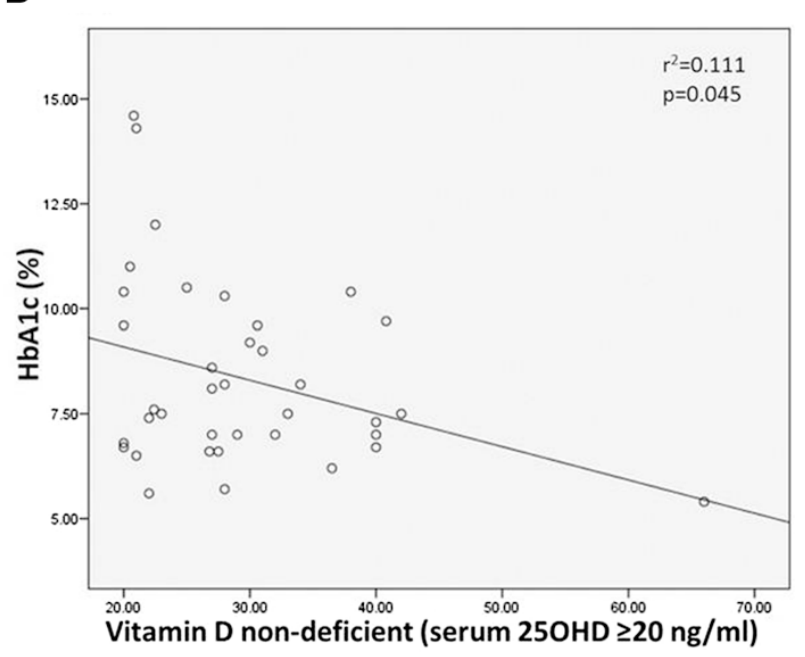

C

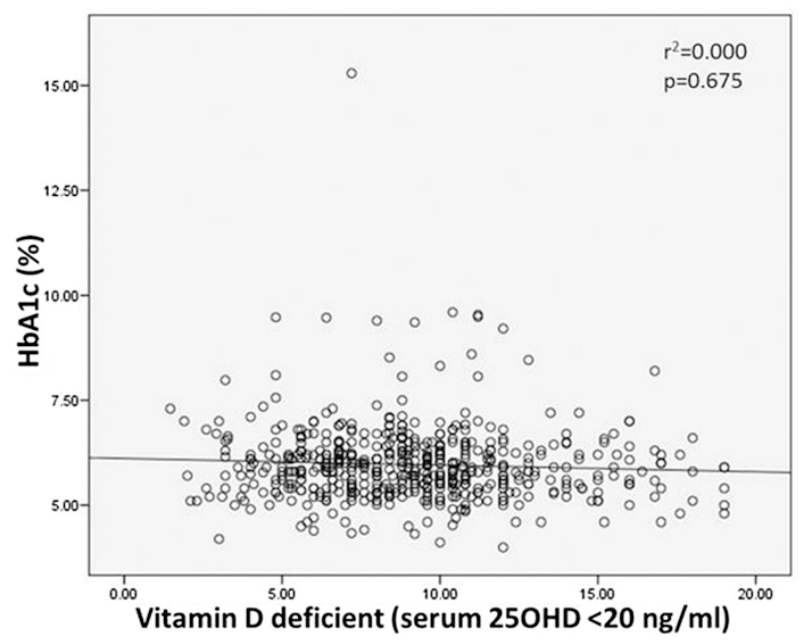

D

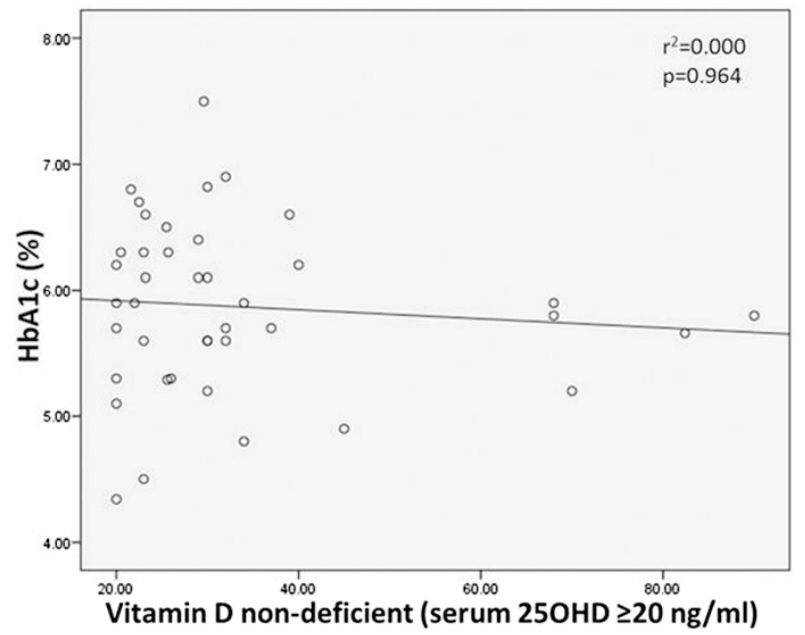

Figure 1 Relationship between vitamin D and HbA1c in deficient and non-deficient T2DM and Controls. A. Relationship between vitamin D deficient T2DM cases and HbA1c. B. Relationship between vitamin D non-deficient T2DM cases and HbA1c. C. Relationship between vitamin D deficient Controls and HbA1c. D. Relationship between vitamin D non-deficient Controls and HbA1c.

been argued by Lo et al. that to meet an adequate requirement of vitamin $\mathrm{D}$, people in India require sun exposure almost double than Caucasians due to increased skin pigmentation [20-22]. Life style factors like in-door working or working in close environment with minimum sun exposure is also likely for high prevalence of vitamin D deficiency in our population. Normal office hours in India are usually from 11 am to $7 \mathrm{pm}$ while maximum sun exposure and absorption is between 11 am to $2 \mathrm{pm}$ with an UV index of 7-9 required for conversion of 7-dehydrocholesterol to pre-vitamin $\mathrm{D}_{3}$ [18]. But this seems to be unrealistic as being a tropical country summers in India are very hot, forcing most of its people to stay indoor during this time. This results in low exposure to the sunlight contributing for very low vitamin D status in our population.

Study by Macdonald et al. [23] has suggested that vitamin D status might not be the only marker of ill health, but also an indicator of lifestyle of an individual like indoor working with restrictions of sunlight exposure, low mobility, dietary habits that might affect long-term health.

Though most of the observational studies cannot demonstrate the cause and effect related to vitamin D, lower vitamin D status might be a reflection of sedentary lifestyle and chronic non-specific illness. It can also be argued that the people with normal levels of vitamin D are in overall good health with better lifestyle and normal 


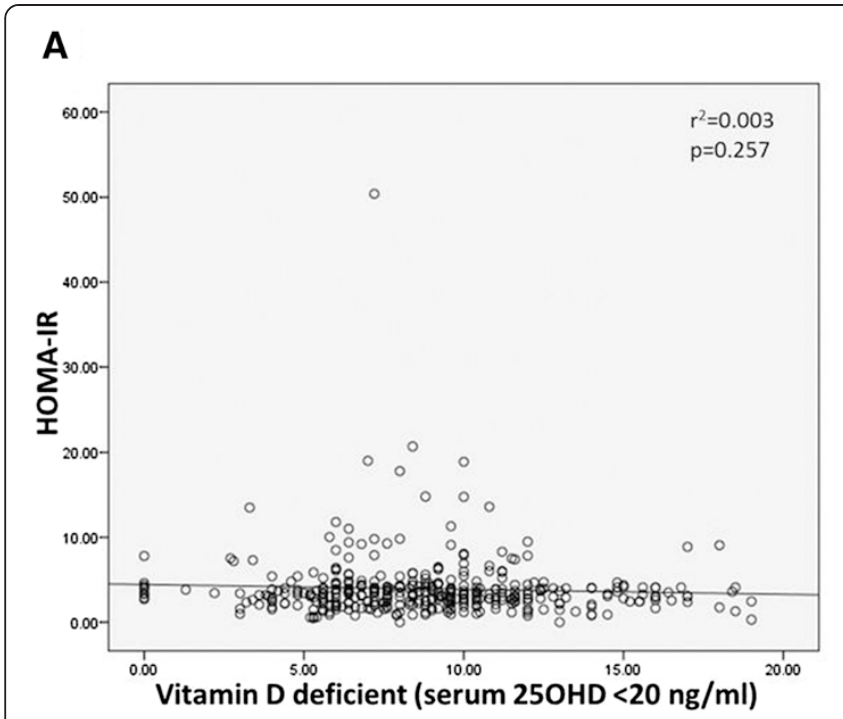

B

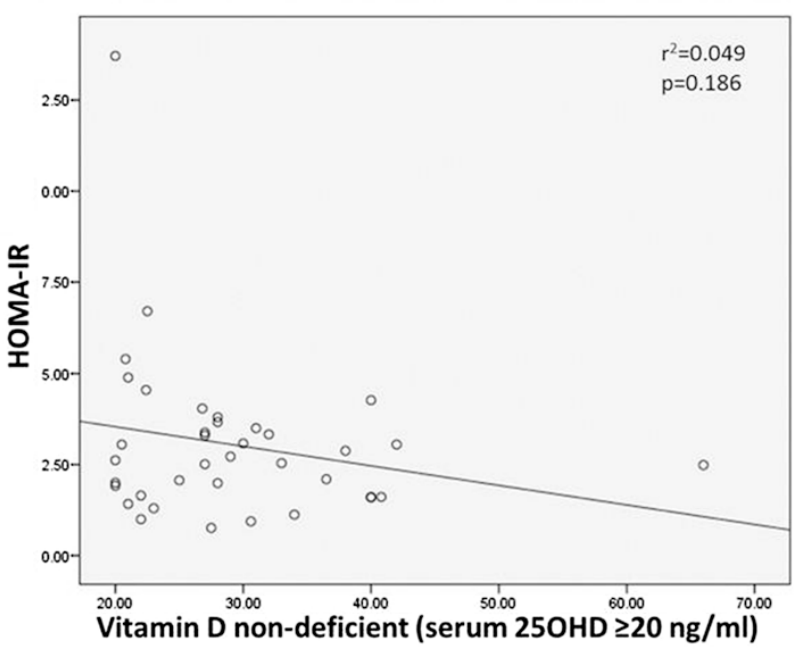

C

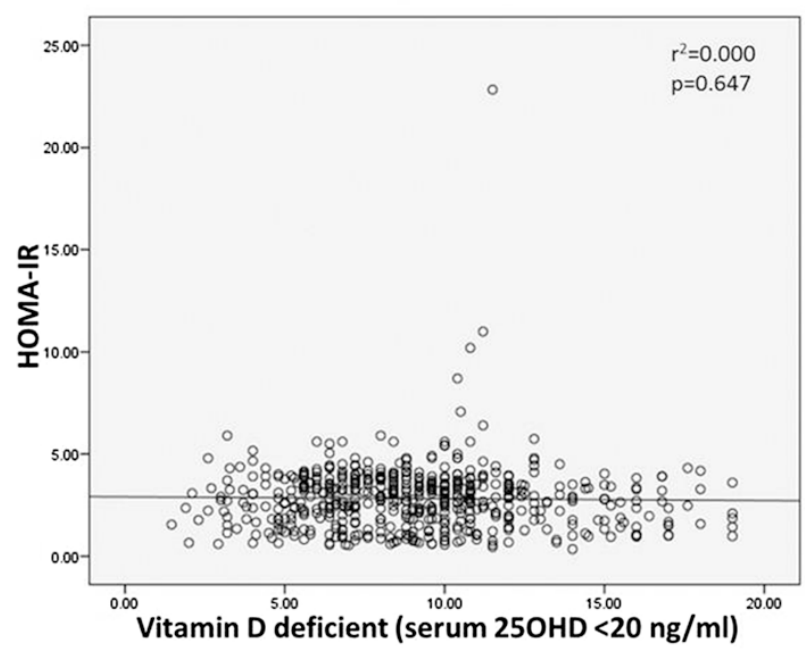

D

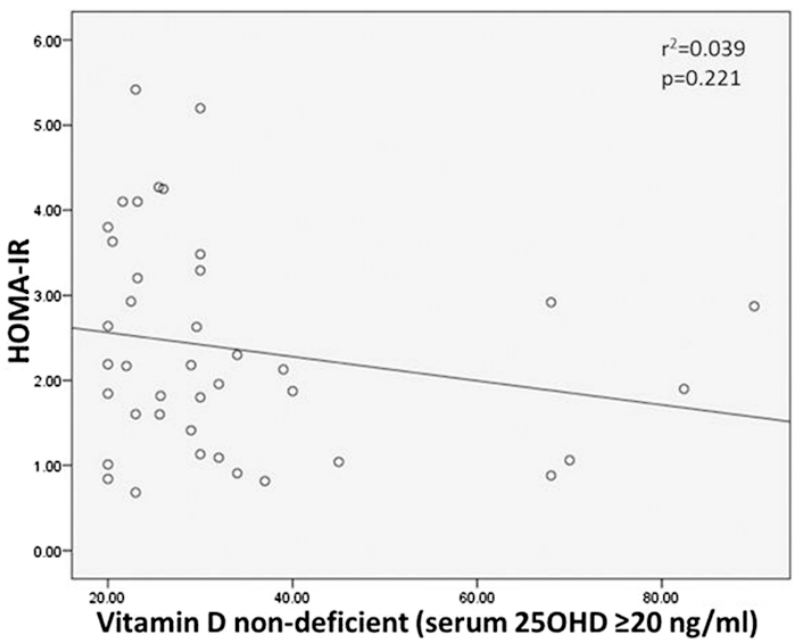

Figure 2 Relationship between vitamin D and HOMA-IR in deficient and non-deficient T2DM and Controls. A. Relationship between Vitamin D deficient T2DM cases and HOMA-IR. B. Relationship between Vitamin D non-deficient T2DM cases and HOMA-IR. C. Relationship between Vitamin D deficient Controls and HOMA-IR. D. Relationship between Vitamin D non-deficient Controls and HOMA-IR.

weight [24]. Although in a review by Pittas et al. an association between T2DM and low vitamin-D levels has been demonstrated [10]. Nonetheless, vitamin-D supplementation was not found to be effective in reducing HbA1c as stated by Melville in his news report [25]. Our finding of absence of significant association of hemoglobin glycation with vitamin D further questions its definitive role in T2DM except for poor lifestyle in our overall population. Luo et al. also showed that within T2DM subjects, regardless of a common finding of vitamin D deficiency, low vitamin $\mathrm{D}$ is associated neither with increased prevalence of the metabolic syndrome, nor is there any association with glycemic control [17].
Several mechanisms like activation of vitamin D receptor and calcium homeostasis involving impaired pancreatic- $\beta$ cell function and insulin resistance in T2DM have been suggested [10]. This has been confirmed by in vitro studies in animal models suggesting its role in improving insulin sensitivity and secretion $[10,17,26]$, though the associations between 25OHD, glucose homeostasis, and insulin resistance in humans seems to be inconsistent [26]. Also a number of studies have shown a consistent inverse association between vitamin $\mathrm{D}$ level or vitamin $\mathrm{D}$ intake on the incidence of T2DM [3,4], but our study could not demonstrate such relationship. Similar observation has been made in studies from New Zealand overweight adult population 
and British Caucasians demonstrating a weak relationship between HbA1c and vitamin D levels [27,28]. In a recent study by Davidson et al. on subjects unknown to have diabetes failed to demonstrate the effect of vitamin $\mathrm{D}$ supplementation to predict the development of diabetes in pre-diabetic and those with low vitamin D level compared to placebo group [29]. As with the progression in the duration of T2DM, the $\beta$-cell reserve attenuates [30], but in our study we could not observe significant association between HbA1c and HOMA-IR with $25 \mathrm{OHD}$ taking into account with the duration of T2DM.

An Australian study by Elkassaby et al. [31] recently observed a transient improvement in glycemia in T2DM with oral $\mathrm{D}_{3}$ supplementation without change in either HbA1c or beta cell function and concluded that high dose $\mathrm{D}_{3}$ has a little or no therapeutic benefit. A similar study from UAE [32] has also reported no significant change in HbA1c levels after six month of supplementation with vitamin $\mathrm{D}_{3}$ in vitamin D-deficient obese T2DM patients of Emirati population. A study performed on Indian subjects residing in New Zealand [33] has shown a significant correlation between insulin sensitivity and IR and decrease in FI with vitamin D supplementation while there was a significant negative correlation between $\mathrm{HbA1c}$ and vitamin D levels due to supplementation in South Asian subjects in UK [34]. Though, both the studies were carried out on relatively smaller populations as compared to the one under report. Furthermore, in a review by Pittas et al. it was shown at least in seven trials that vitamin D supplementation has no role on glycemic measures and HOMA-IR (as an indicator of insulin resistance) in participants with normal glucose tolerance [35]. In addition, no effect of vitamin D supplementation was evident in four out of five trials (with participants from normal glucose tolerance) that reported insulin resistance as an outcome [35]. A review study by George et al. again argued against vitamin D supplementation for improving glycemic control and insulin resistance in T2DM and non-diabetic subjects [36]. Moreover, a recent study by Al-Shoumer et al. demonstrated the prevalence of vitamin D deficiency in insulin resistant T2DM and normal subjects, where insulin resistance was not found to be influencing the status of vitamin D [37]. Further confirming this, Kampmann et al. and Witham et al. showed that improvement in vitamin $\mathrm{D}$ status may increase insulin secretion but did not improve insulin resistance and HbAlc in patients with T2DM $[38,39]$. This is in concordance with our findings that vitamin D levels did not show any significant linear association with HOMA-IR status in T2DM cases as well as control subjects. This is possibly because the inflammatory mechanisms are extremely stimulated by the diabetic milieu or the $\beta$-cell dysfunction, and insulin resistance is more severe and less reversible by extended duration of diabetes as explained by Luo et al. [17].

\section{Limitation}

The study was a cross sectional study, carried out on urban metropolitan subjects where rural subjects were not included. Moreover, the method used to measure vitamin D levels was ELISA method which is less sensitive to LCMS/MS method.

\section{Conclusion}

Though vitamin D deficiency is prevalent in T2DM and non- diabetic control subjects, its relationship in glycation control or insulin resistance in T2DM subjects could not be confirmed in our population. This is potentially an important finding for public health, demonstrating that improvement in vitamin D status is not the only factor responsible for better health of the individuals but lifestyle and dietary changes seem to play a role which will improve the overall health including hemoglobin glycation and insulin resistance along with vitamin D levels. Whether vitamin D supplementation can delay the onset of diabetes remains to be recognized. Therefore, future studies to clarify the efficacy of vitamin D supplementation in preventing diabetes and pre-diabetes are warranted, especially in populations at high risk.

\section{Abbreviations}

T2DM: Type 2 Diabetes Mellitus; HbA1c: Glycated Hemoglobin; HOMA-IR: Homeostasis Model of Assessment-Insulin Resistance Index; FBS: Fasting Blood Sugar; PPBS: Post prandial Blood Sugar; IDF: International Diabetes Federation; BMI: Body Mass Index; FI: Fasting Insulin.

\section{Competing interests}

The authors declare no conflict of interest that could be perceived as prejudicing the impartiality of this research. None of the authors is involved in the financial support that might potentially bias his or her work.

\section{Authors' contributions}

JS: Conceived and designed the experiments; agreed with manuscript results and conclusions; made critical revisions and approved final version; jointly developed the structure and arguments for the paper. AS: Analysed and interpreted the data, wrote the manuscript; agreed with manuscript results and conclusions. FS: Conceived and designed the experiments; agreed with manuscript results and conclusions; made critical revisions and approved final version. ST: Scrutinized the analysis and interpretation of the data, made critical revisions and approved final version. NS: Made critical revisions and approved final version. PT: Made critical revisions and approved final version. ML: Made critical revisions and approved final version. RV: Conceived and designed the experiments; made critical revisions and approved final version. All authors reviewed and approved of the final manuscript.

\section{Acknowledgements}

Sincere thanks to Mrs. Jyothi Lekshmi, Dr. Nutan Nabar for their partial technical help. Sincere thanks to clinicians for their cooperation and kind referrals. Special thanks to the staff members of the institute without whose cooperation this study would be difficult. We wish to express pure deep sense of gratitude for the participating subjects and their families who have made this study possible.

\section{Funding sources}

This part of the study was funded by Gujarat Institute of Chemical Technology (GICT) which we gratefully acknowledge. 


\section{Author details}

${ }^{1}$ Department of Biochemistry and Molecular Genetics, FRIGE's Institute of Human Genetics, FRIGE House, Jodhpur Gam Road, Satellite, Ahmedabad 380015, India. ${ }^{2}$ Unit of Endocrine and Metabolic Disorders, Kasturba Health Society, Medical Research Centre, Mumbai 400056, India. ${ }^{3}$ Department of Diabetes and Endocrinology, Sterling Hospital, Ahmedabad 380052, India. ${ }^{4}$ Gujarat Diabetic Association, Ahmedabad 380007, India.

Received: 29 October 2014 Accepted: 18 February 2015

Published online: 26 February 2015

\section{References}

1. American Diabetes Association. Diagnosis and classification of diabetes mellitus. Diabetes Care. 2009;32:62-7.

2. IDF: One adult in ten will have diabetes by 2030. IDF Press release; 2011 [http://www.idf.org/media-events/press-releases/2011/diabetes-atlas-5th-edition], accessed on 29th August 2014

3. Pittas AG, Harris SS, Stark PC, Dawson-Hughes B. The effects of calcium and vitamin D supplementation on blood glucose and markers of inflammation in nondiabetic adults. Diabetes Care. 2007:30(4):980-6.

4. Pittas AG, Dawson-Hughes B. Vitamin D and Diabetes. J Steroid Biochem Mol Biol. 2010;121(1-2):425-9.

5. Alvarez JA, Ashraf A. Role of vitamin D in insulin secretion and insulin sensitivity for glucose Homeostasis. Int J Endocrinol. 2010;2010:351-85.

6. Heshmat R, Malazy OT, Ahranjani SA, Shahbazi S, Khooshehchin G, Bandarian $F$, et al. Effect of vitamin D on insulin resistance and anthropometric parameters in Type 2 diabetes; a randomized double-blind clinical trial. DARU J Pharm Sci. 2012;20:10. doi:10.1186/2008-2231-20-10.

7. Talaei A, Mohamadi M, Adgi Z. The effect of vitamin D on insulin resistance in patients with type 2 diabetes. Diabetol Metabol Syndr. 2013;5:8. doi:10.1186/1758-5996-5-8

8. Chiu KC, Chu A, Go VL, Saad MF. Hypovitaminosis D is associated with insulin resistance and beta cell function. Am J Clin Nutr. 2004:79:820-5.

9. Hutchinson MS, Figenschau Y, Njølstad I, Schirmer H, Jorde R. Serum 25-hydroxy vitamin D levels are inversely associated with glycated haemoglobin $(\mathrm{HbA}(1 \mathrm{c}))$. The Tromsø Study Sc and J Clin Lab Invest. 2011;71(5):399-406.

10. Pittas A, Lau J, Hu F, Dawson-Hughes B. Review: the role of vitamin D and calcium in type 2 diabetes. A systematic review and meta-analysis. J Clin Endocrinol Metab. 2007:92:2017-29.

11. Kositsawat J, Freeman VL, Gerber BS, Geraci S. Association of A1C levels with vitamin D status in U.S. adults: data from the National Health and Nutrition Examination Survey. Diabetes Care. 2010;33:1236-8.

12. Zhao G, Ford ES, Li C. Associations of serum concentrations of 25 -hydroxyvitamin $D$ and parathyroid hormone with surrogate markers of insulin resistance among U.S. adults without physician-diagnosed diabetes: NHANES, 2003-2006. Diabetes Care. 2010;33:344-7.

13. World Health Organization Diabetes Programme. About Diabetes. www.who.int/ diabetes/action_online/basics/en/index2.html, accessed on 13 ${ }^{\text {th }}$ January 2015.

14. Ritu G, Ajay G. Vitamin D Deficiency in India: Prevalence, Causalities and Interventions. Nutrients. 2014:6:729-75.

15. Matthews DR, Hosker JP, Rudenski AS, Naylor BA, Treacher DF, Turner RC. Homeostasis model assessment: Insulin resistance and $\beta$-cell function from fasting plasma glucose and insulin concentrations in man. Diabetologia. 1985;28:412-9.

16. Sample Size Calculator. Raosoft Inc. [http://www.raosoft.com/samplesize. html], accessed on $15^{\text {th }}$ August 2014.

17. Luo C, Wong J, Brown M, Hooper M, Molyneaux L, Yue DK. Hypovitaminosis $D$ in Chinese type 2 diabetes: Lack of impact on clinical metabolic status and biomarkers of cellular inflammation. Diab Vasc Dis Res. 2009:6:194-209.

18. Harinarayan CV, Joshi SR. Vitamin D status in India-Its implications and Remedial Measures. J Assoc Physicians India. 2009:57:40-8.

19. Harinarayan CV, Holick MF, Prasad UV. Vitamin D status and sun exposure in India. Dermato-Endocrinol. 2013;5(1):130-41.

20. Lo CW, Paris PW, Holick MF. Indian and Pakistani immigrants have the same capacity as Caucasians to produce vitamin D in response to ultraviolet irradiation. Am J Clin Nutr. 1986;44:683-5.

21. Kift R, Berry JL, Vail A, Durkin MT, Rhodes LE, Webb AR. Lifestyle factors including less cutaneous sun exposure contribute to starkly lowe vitamin D levels in U.K. South Asians compared with the white population. Br J Dermatol. 2013;169(6):1272-8. doi:10.1111/bjd.12518.
22. Lips $P$, van Schoor NM, de Jongh RT. Diet, sun, and lifestyle as determinants of vitamin D status. Ann N Y Acad Sci. 2014:1317:92-8. doi:10.1111/nyas.12443.

23. Macdonald HM, Wood AD, Fraser WD, Simpson WD. Vitamin D status and ill health. The Lancet Diabetes Endocrinol. 2014:2(4):8-9.

24. Matthews SE. Researchers Question Vitamin D's Link to Diabetes. www. everydayhealth.com/diabetes/researchers-question-vitamin-ds-link-todiabetes-9935.aspx. October 23, 2013, accessed on 27 $7^{\text {th }}$ August 2014

25. Melville NA. Large Review Casts Cloud Over Vitamin-D Health Benefits. Medscape Medical News. Dec 05, 2013. [http://www.medscape.com/viewarticle/ 815472], accessed on $27^{\text {th }}$ August 2014.

26. Eftekhari $\mathrm{MH}$, Akbarzadeh $\mathrm{M}$, Dabbaghmanesh $\mathrm{MH}$, Hasanzadeh J. Impact of treatment with oral calcitrol on glucose indices in type 2 diabetes mellitus patients. Asia Pac J Clin Nutr. 2011:20(4):521-6.

27. McGill AT, Stewart JM, Lithander FE, Strik CM, Poppitt SD. Relationships of low serum vitamin $D_{3}$ with anthropometry and markers of the metabolic syndrome and diabetes in overweight and obesity. Nutr J. 2008;7:4. doi:10.1186/1475-2891-7-4.

28. Hyppönen E, Power C. Vitamin D status and glucose homeostasis in the 1958 British birth cohort: the role of obesity. Diabetes Care. 2006:29:2244-6.

29. Davidson MB, Lee ML, Duran P, Friedman TC. High-Dose Vitamin D Supplementation in People With Prediabetes and Hypovitaminosis D. Diabetes Care. 2013:36:260-6. doi:10.2337/dc12-1204

30. Fonseca VA. Defining and Characterizing the Progression of Type 2 Diabetes. Diabetes Care. 2009:32(2):S151-6. doi:10.2337/dc09-S301.

31. Elkassaby S, Harrison LC, Mazzitelli N, Wentworth JM, Colman PG, Spelman T, et al. A randomised controlled trial of high dose vitamin D in recent-onset type 2 diabetes. Diabetes Res Clin Pract. 2014;106(3):576-82. doi:10.1016/ j.diabres.2014.08.030.

32. A Sadiya A, Ahmed SM, Carlsson M, Tesfa Y, George M, Ali SH, Siddieg HH, Abusnana S. Vitamin D supplementation in obese type 2 diabetes subjects in Ajman, UAE: a randomized controlled double-blinded clinical trial. Eur J Clin Nutr. advance online publication 19 November 2014; doi:10.1038/ejcn.2014.251

33. Sabherwal $S$, Bravis $V$, Devendra D. Effect of oral vitamin D and calcium replacement on glycaemic control in South Asian patients with type 2 diabetes. Int J Clin Pract. 2010;64(8):1084-9. doi:10.1111/j.1742-1241.2010.02372.x.

34. Pamela R, Stonehouse W, Coad J. Vitamin D supplementation reduces insulin resistance in South Asian women living in New Zealand who are insulin resistant and vitamin D deficient - a randomised, placebo-controlled trial. Br J Nutr. 2010;103:549-55. doi:10.1017/S0007114509992017.

35. Mitri J, Muraru MD, Pittas AG. Vitamin D and type 2 diabetes: a systematic review. Eur J Clin Nutr. 2011:65(9):1005-15.

36. George PS, Pearson ER, Witham MD. Effect of vitamin D supplementation on glycaemic control and insulin resistance: a systematic review and meta-analysis. Diabet Med. 2012;29:142-50. doi:10.1111/j.1464-5491.2012.03672x.

37. Al-Shoumer KA, Al-Asoosi AA, Ali AH, Nair VS. Does insulin resistance in type 2 diabetes alter vitamin D status? Prim Care Diabetes. 2013;7(4):283-7.

38. Kampmann U, Mosekilde L, Juhl C, Moller N, Christensen B, Rejnmark L, et al. Effects of 12 weeks high dose vitamin D3 treatment on insulin sensitivity, beta cell function, and metabolic markers in patients with type 2 diabetes and vitamin D insufficiency - a double-blind, randomized, placebo-controlled trial. Metabolism. 2014;63(9):1115-24.

39. Witham MD, Dove FJ, Dryburgh M, Sugden JA, Morris AD, Struthers AD. The effect of different doses of vitamin D3 on markers of vascular health in patients with type 2 diabetes: a randomised controlled trial. Diabetologia. 2010;53:2112-9. doi:10.1007/s00125-010-1838-1.

\section{Submit your next manuscript to BioMed Central and take full advantage of:}

- Convenient online submission

- Thorough peer review

- No space constraints or color figure charges

- Immediate publication on acceptance

- Inclusion in PubMed, CAS, Scopus and Google Scholar

- Research which is freely available for redistribution 